\title{
MODEL EKONOMI SUMBERDAYA IKAN DEMERSAL YANG LESTARI DI PERAIRAN KABUPATEN REMBANG
}

\author{
Sofyan Eko Putra \\ Magister Ilmu Ekonomi dan Studi Pembangunan, Universitas Diponegoro \\ e-mail: sofyan.eko@gmail.com
}

\begin{abstract}
ABSTRAK
This study examines the level of utilization of demersal fish resources by using Schaefer Surplus Production Model and Gordon-Schaefer Bioeconomics Model. Fishing effort is a strategic effort in improving the welfare and life quality of coastal communities of Rembang District. This study aims to estimate the Maximum Sustainable Yield (MSY), Maximum Economic Yield (MEY), Open Accsess Equilibrium (OAE), and Economic Rents (ER) of sustainable demersal fish resources in Rembang District. Bioeconomics assessments was conducted by using secondary data: production data (catch) and unit vessel (effort) 2001-2006, and primary data: the average price of demersal fish catches per year, and the average cost per unit per vessel in years. The results showed that the level of sustainable production $\left(C_{M S Y}\right)$ and sustainable efforts $\left(E_{M S Y}\right)$ demersal fish resources was 4,943,425.25 $\mathrm{kg}$ per year and 164 ships per year. These results indicate that the rate of utilization of demersal fish resources Rembang district are 97\% (2001), 117\% (2002), 92\% (2005) and had been overfishing in 2002 or exceed the Total Allowable Catch (FAO, 1995) is 80\% of the value of sustainable production $\left(C_{M S Y}\right)$. Optimization profit $\left(E R_{M E Y}\right)$ of demersal fisheries can still be achieved by reducing the number of fleet at economic efforts $\left(E_{M E Y}\right): 106$ units per year and optimum economic production $\left(C_{M E Y}\right): 4,323,595.25 \mathrm{~kg}$ per year.
\end{abstract}

Keywords: Bioeconomic, Overfishing, Demersal Fish, Rembang District.

\section{PENDAHULUAN}

Indonesia memiliki panjang garis pantai $81.000 \mathrm{~km}$ terpanjang kedua di dunia setelah Kanada, dengan bentang wilayah Indonesia dari ujung barat (Sabang) sampai Timur (Merauke) setara dengan London sampai Baghdad. Bentang ujung utara (Kepulauan Satal) dan selatan (Pulau
}

Rote) setara dengan jarak Jerman sampai dengan al-Ajazair. Potensi lestari sumberdaya ikan laut diperkirakan sebesar 6,4 juta ton per tahun dengan jumlah tangkapan yang diperbolehkan (Total Allowable Catch/TAC) sebesar 5,12 juta ton per tahun atau sekitar 80 persen dari potensi lestari. Sedangkan, potensi perikanan tangkap Indonesia lebih dari USD 15 milliar (Riyadi, 2004). 


\section{Gambar 1}

\section{Status Pemanfaatan Sumberdaya Perikanan} Laut di Indonesia

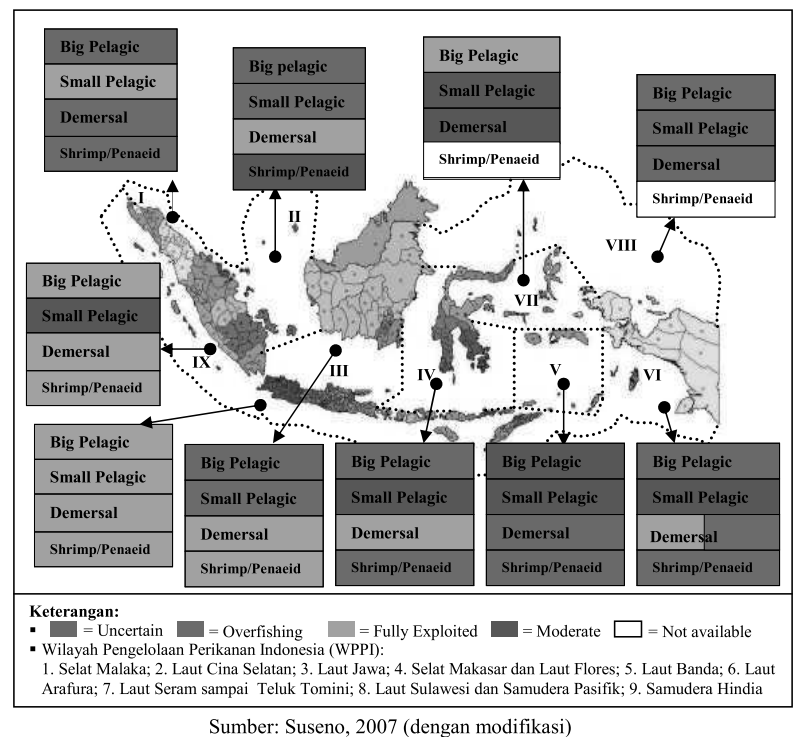

Potensi ekonomi yang tinggi tersebut akan tercapai apabila eksploitasi khususnya perikanan tangkap tidak melebihi jumlah tangkapan yang diperbolehkan (total allowable catch), namun fakta menunjukkan praktek eksploitasi yang berlebih (overfishing) berlangsung hingga kini.

Kabupaten Rembang sebagai salah satu kabupaten dengan nilai produksi perikanan tangkap tertinggi di Propinsi Jawa Tengah memiliki andil dalam kontribusi overfishing di Wilayah Pengelolaan Perikanan Indonesia (WPPI) III, yakni Laut Jawa. Status pemanfaatan sumberdaya ikan di Laut Jawa (lihat Gambar 1), khususnya ikan demersal memiliki status penangkapan yang telah dieksploitasi secara penuh (fully exploited).

Dinas Perikanan dan Kelautan Kabupaten Rembang tahun 2006 (lihat Gambar 2) menunjukkan perkembangan produksi sumberdaya ikan demersal semakin menurun, $4.804 .559 \mathrm{~kg}$ (2001) hingga $3.227 .845 \mathrm{~kg}$ (2006), sedangkan jumlah armada kapal cantrang semakin meningkat. Misuari dan Sutardji (2006) menjelaskan kapal cantrang merupakan alat tangkap ikan demersal yang dominan digunakan nelayan Kabupaten Rembang.

Gambar 2

\section{Produksi Ikan Demersal dan Jumlah Kapal Cantrang di Kabupaten Rembang Tahun 2001-2006}

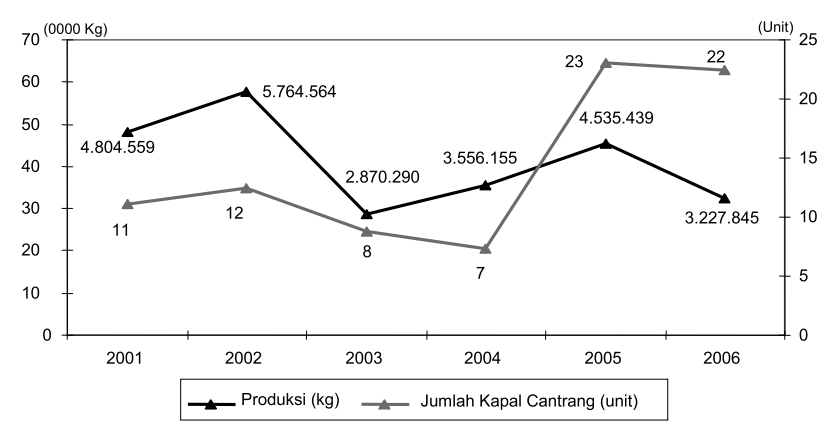

Sumber: Dinas Perikanan dan Kelautan Kabupaten Rembang (diolah), 2007

Melihat permasalahan tersebut, untuk menerapkan konsepsi pemanfaatan sumberdaya perikanan demersal yang menguntungkan secara ekonomi dengan tetap memperhatikan keberlanjutan sumberdaya ikan demersal di Kabupaten Rembang, maka diperlukan pendekatan untuk mengkaji permasalahan tersebut. Oleh karena itu, penelitian ini akan mengkaji aspek biologi dan aspek ekonomi sumberdaya perikanan demersal di Kabupaten Rembang yang diukur melalui estimasi MSY (Maximum Sustainable Yield), OAE (Open Accsess Equilibrium), dan MEY (Maximum Economic Yield), ER (Economic Rent).

\section{REVIEW LITERATUR DAN HIPOTESIS}

\section{Fungsi Produksi Perikanan}

Fungsi produksi perikanan jangka pendek adalah hubungan antara tangkapan (catch) dan upaya (effort) sedangkan dalam jangka panjang merupakan hubungan antara penangkapan dan rata-rata penangkapan yang dapat diperoleh pada 
waktu tertentu tanpa mempengaruhi stok ikan (Anderson 1986; Himawan 2005).

Menurut teori produksi, ada empat tahapan produksi sumberdaya alam dilihat dari jumlah penggunaan inputnya yaitu (lihat Gambar 3): tahap I, produksi yang dapat mencapai keuntungan ekonomi (profit) yang maksimum (Maximum Economic Yield), tahap II, produksi yang dapat mencapai jumlah produksi fisik yang maksimum (Maximum Sustainable Yield), tahap III, produksi yang tidak memperoleh untung atau rugi (break even point atau open acsess), dan tahap IV, produksi yang merugi (Anderson 1986; Susilowati 2006).

\section{Gambar 3}

Hubungan antara Maximum Economic Yield (MEY), Maximum Sustainable Yield (MSY), dan Open Accsess (OA)

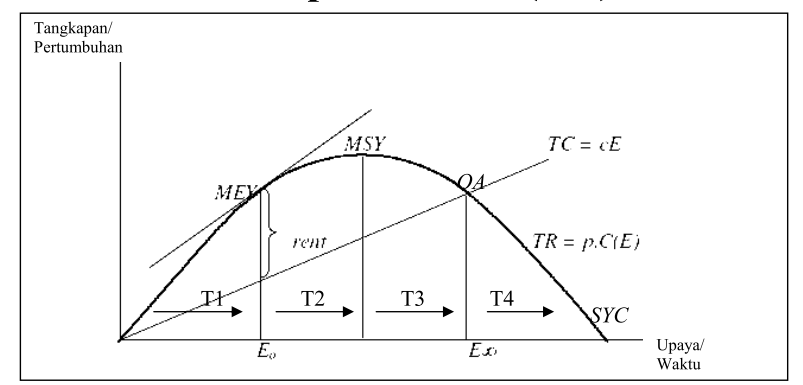

Keterangan:

SYC : Sustainable Yield Curve

Ti : Tahap Produksi

MEY : Maximum Economic Yield

Ei : Effort (upaya)

MSY : Maximum Sustainable Yield

Sumber: Susilowati, 2006 (dengan modifikasi)

\section{Model Surplus Produksi}

Model surplus produksi diperkenalkan oleh Graham (1935), akan tetapi model ini lebih sering diacu sebagai Model Schaefer. Tujuan penggunaan model surplus produksi adalah untuk menentukan tingkat upaya optimum (effort MSY/ $\mathrm{E}_{\mathrm{MSY}}$ ), yaitu suatu upaya yang dapat menghasilkan suatu hasil tangkapan maksimum yang lestari tanpa mempengaruhi produktivitas stok secara jangka panjang, yang disebut hasil tangkapan maksimum lestari (maximum sustainable yield/ MSY) (Sparre dan Venema, 1999).

Model surplus produksi yang digunakan untuk menentukan MSY dan $\mathrm{E}_{\mathrm{MSY}}$ ini menyangkut hubungan antara kelimpahan dari sediaan ikan sebagai massa yang uniform dan tidak berhubungan dengan komposisi dari sediaan seperti proporsi ikan tua atau besar. Kelebihan model surplus produksi ini adalah tidak banyak memerlukan data, yaitu hanya data hasil tangkapan dan upaya penangkapan atau hasil tangkapan per satuan upaya (Mukhlisa, 2006)

Model Schaefer (1954) berbasis pada asumsi model keseimbangan. Model tersebut berasumsi bahwa stok sumber daya ikan mengikuti kurva pertumbuhan logistik. Laju pertumbuhan surplus didefinisikan sebagai berikut (Triarso, 2006):

$$
\mathrm{F}(\mathrm{X})=\mathrm{rX}\left(1-\frac{X}{K}\right)
$$

Dimana $\mathrm{F}(\mathrm{X})$ adalah pertumbuhan alami, $\mathrm{X}$ adalah jumlah stok ikan, $\mathrm{K}$ adalah carrying capacity atau daya dukung lingkungan dan $\mathrm{r}$ adalah intrinsic gowth rate.

Persamaan (1) akan menghasilkan kurva parabolic. Untuk mencari pertumbuhan alami yang maksimal, maka dapat dilakukan turunan pertama pada persamaan (1) terhadap stok yang harus sama dengan nol sebagai berikut:

$$
\begin{gathered}
\frac{d F(X)}{d X}=r\left(1-\frac{2 X}{K}\right) . \\
X=\frac{K}{2}
\end{gathered}
$$

Namun persamaan $\mathrm{X}=\mathrm{K} / 2$ yang mencerminkan MSY tersebut belum memperhitungkan adanya kegiatan penangkapan ikan. 
Jumlah hasil tangkapan ikan atau catch ( C ) dipengaruhi oleh jumlah stok ikan (X), dan upaya kegiatan penangkapan atau effort (E) yang dilakukan. Kegiatan penangkapan ikan mengikuti persamaan berikut :

$\mathrm{C}(\mathrm{E}, \mathrm{X})=\mathrm{q} \mathrm{EX}$

Dimana q adalah konstanta dari koefisien daya tangkap. Keseimbangan akan terjadi apabila antara pertumbuhan alami sebanding dengan laju penangkapan atau $\mathrm{dX} / \mathrm{dt}=\mathrm{F}(\mathrm{X})-\mathrm{C}(\mathrm{E}, \mathrm{X})=0$.

Oleh karena itu, persamaan tersebut dapat diuraikan sebagai berikut:

$$
\begin{aligned}
& r X\left(1-\frac{X}{K}\right)-q E=0 \\
& X=K\left(1-\frac{q E}{r}\right)
\end{aligned}
$$

Dengan memasukkan persamaan (6) ke dalam persamaan (4), maka diperoleh :

$$
C=q K E\left(1-\frac{q E}{r}\right)
$$

Selanjutnya, persamaan (7) disederhanakan menjadi :

$\mathrm{C}=\alpha \mathrm{E}-\beta \mathrm{E}^{2}$.

dimana $\alpha=\mathrm{qK}$ dan $\beta=\mathrm{q} 2 \mathrm{~K} / \mathrm{r}$. Persamaan (8) dapat disederhanakan lagi menjadi :

$\mathrm{CPUE}=\alpha-\beta \mathrm{E}$

dimana CPUE atau Catch per Unit Effort adalah C/E.

\section{Gambar 4}

Hubungan antara Catch per Unit Effort

(CPUE) dan Effort

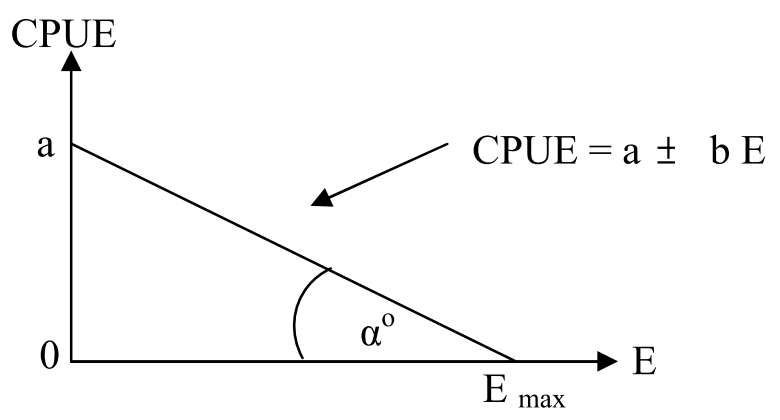

Sumber: Mulyadi, 2007

Untuk mendapatkan hasil tangkapan optimal yang lestari atau MSY, maka perlu dilakukan dengan menurunkan persamaan (8), yaitu menjadi $\mathrm{dC} / \mathrm{d} \mathrm{E}=0$ (first order condition), sehingga diperoleh a $-2 \mathrm{bE}=0$. Selanjutnya, akan diperoleh persamaan effort yang optimal sebagai berikut :

$\mathrm{E}_{\mathrm{MSY}}=\alpha / 2 \beta$.

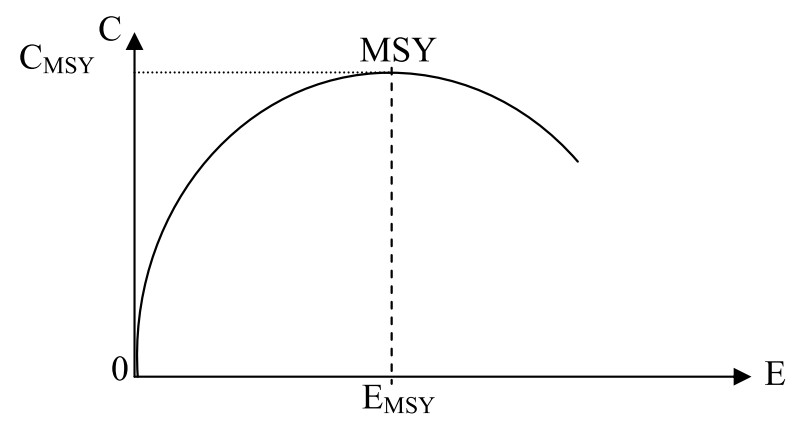

Sumber: Mulyadi, 2007

Dengan memasukkan persamaan (10) ke dalam persamaan $(4,8)$, yaitu $\mathrm{E}=\mathrm{E}_{\mathrm{MSY}}$, maka akan diperoleh persamaan catch $(\mathrm{C})$ yang optimal sebagai berikut:

$\mathrm{C}_{\mathrm{MSY}}=\alpha^{2} / 4 \beta$. 


\section{Model Bioekonomi Gordon-Schaefer}

Pendekatan Bioekonomi adalah pendekatan yang memadukan kekuatan ekonomi yang mempengaruhi industri penangkapan dan faktor biologis yang menentukan produksi dan suplai ikan (Clark, 1985; Purwanto, 2006).

Anderson (1986) mengemukakan bahwa asumsi yang digunakan dalam melakukan perhitungan (total revemeu) TR dan total cost (TC) adalah harga dari produk perikanan dan unit cost dari effort (biaya per unit) diasumsikan konstan, sehingga dalam jangka panjang dapat dijelaskan dalam gambar 6 .

Adapun Total economic rent (p) diperoleh dari mengurangi pendapatan dengan pengeluaran. Apabila menggunakan pendekatan open acces equilibrum (OAE), maka harus memenuhi ketentuan :

$\pi=\mathrm{TR}-\mathrm{TC}=0$

$\mathrm{TR}=\mathrm{TC}$

dimana TR adalah total revenue, sedangkan TC adalah total cost.

Total Revenue dihitung berdasarkan persamaan :

$\mathrm{TR}=\mathrm{p} \mathrm{C}$

dimana $\mathrm{p}$ adalah harga per kilogram dari ikan, dan $\mathrm{C}$ adalah total tangkapan (catch).

Sedangkan total cost dihitung dengan persamaan :

$\mathrm{TC}=\mathrm{c} \mathrm{E}$

Dimana c adalah biaya per unit upaya, dan E adalah upaya tangkap.

Dengan menggunakan persamaan (14) dan (15) ke dalam persamaan (13), maka diperoleh persamaan :

$\mathrm{p} \mathrm{C}=\mathrm{c} \mathrm{E}$

Dengan memasukkan persamaan (8) ke dalam persamaan (16) akan diperoleh persamaan :

$p\left(\alpha E-\beta E^{2}\right)=c E$

Dengan menggunakan persamaan (17) akan diketahui tingkat effort dan catch optimal dengan menggunakan pendekatan OAE sebagai berikut :

$\mathrm{E}_{\mathrm{OAE}}=(\mathrm{p} \alpha-\mathrm{c}) /(\mathrm{p} \beta)$

$\mathrm{C}_{\mathrm{OAE}}=\alpha \mathrm{E}_{\mathrm{OAE}}-\beta\left(\mathrm{E}_{\mathrm{OAE}}\right)^{2}$

Apabila menggunakan pendekatan MEY, maka mengikuti ketentuan: $\mathrm{MR}=\mathrm{MC}$, dimana $\mathrm{MR}$ adalah marginal revenue dan $\mathrm{MC}$ adalah marginal cost. Hal itu dapat diperoleh dengan menurunkan fungsi TR dan TC terhadap $\mathrm{E}$ atau $\mathrm{dTR} / \mathrm{dE}=\mathrm{dTC} / \mathrm{dE}$. Dengan demikian akan diperoleh persamaan :

$\mathrm{p}(\alpha-\beta \mathrm{E})=\mathrm{c}$

Dengan menggunakan persamaan (12), akan diperoleh $\mathrm{E}$ dan $\mathrm{C}$ yang optimal berdasarkan pendekatan MEY sebagai berikut :

$\mathrm{E}_{\mathrm{MEY}}=(\mathrm{p} \alpha-\mathrm{c}) /(2 \mathrm{p} \beta) \ldots \ldots .$.
$\mathrm{C}_{\mathrm{MEY}}=\alpha \mathrm{E}_{\mathrm{MEY}}-\beta\left(\mathrm{E}_{\mathrm{MEY}}\right)^{2}$.

\section{Gambar 6}

Keseimbangan Bioekonomi:

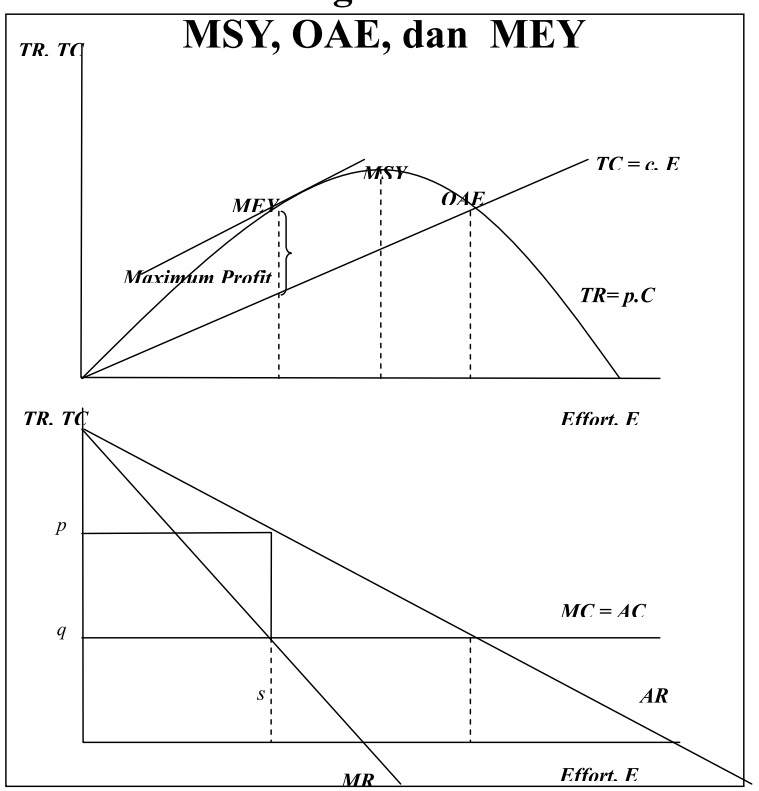

Keterangan:

Keterangan:
$\mathrm{TR}=$ total revenue, $\mathrm{TC}=$ total cost $, \mathrm{E}=\mathrm{Effort}, \mathrm{c}=$ cost per unit effort, $\mathrm{C}=$ catch atau hasil tangkapan, $\mathrm{p}=$ harga ikan, $\mathrm{MC}=$ marginal cost, $\mathrm{MR}=$ marginal revenue, $\mathrm{AC}=$ average cost, $\mathrm{AR}=$ average revenue

Sumber: Anderson, 1986 (dengan modifikasi)

Sumber: Anderson, 1986 (dengan modifikasi) 


\section{Ikan Demersal}

Ikan demersal adalah golongan ikan yang hidupnya di dasar perairan yang terbatas pada daerah sampai kedalaman 100 meter (Direktorat Jenderal Perikanan, 1987). Ikan demersal mempunyai sifat-sifat: aktifitas yang rendah, gerak ruaya perpindahannya yang relatif jauh, dan membentuk gerombolan (schooling) yang tidak terlalu besar (Dwiponggo, 1992).

Dengan ruaya perpindahannya yang dekat perairan, oleh karenanya sumberdaya ikan demersal bisa menggambarkan kondisi Kabupaten Rembang, mengingat wewenang Kabupaten/Kota adalah mengelola sampai dengan 4 mil dalam batas laut propinsi (pasal 18 ayat 4 UU No. 32 Tahun 2004).

\section{Alat Tangkap Cantrang}

Berdasarkan keterangan DPK Kabupaten Rembang, Misuari, dan Sutradji (2006) kapal cantrang merupakan alat tangkap dominan yang digunakan nelayan Kabupaten Rembang untuk penangkapan ikan demersal. Cantrang digunakan untuk menangkap ikan terutama demersal di perairan teritorial pada Jalur I (6 mil ke arah laut) dan II (12 mil ke arah laut) di seluruh perairan Indonesia (Dirjen Pengawasan Sumberdaya Kelautan dan Perikanan, 2004).

\section{Hipotesis}

1. Diduga sumberdaya ikan demersal di Kabupaten Rembang overfishing

2. Diduga usaha penangkapan ikan demersal secara ekonomi tidak dapat dikembangkan lagi.

\section{METODE PENELITIAN}

\section{Data dan Sampel}

Penelitian ini menggunakan data primer dan data sekunder. Data primer untuk bioekonomi, diperoleh dari responden (nelayan/ pemilik kapal cantrang) melalui wawancara yang dipandu dengan kuesioner meliputi: jumlah tangkapan per trip, biaya per trip, harga ikan, musim, dan daerah penangkapan. Sedangkan, data sekunder diperoleh dari Dinas Perikanan dan Kelautan Kabupaten Rembang, dan studi literatur. Penelitian ini dilaksanakan pada bulan Juni-Agustus tahun 2007.

Populasi penelitian ini adalah jumlah unit kapal cantrang yang berada di Kabupaten Rembang. Teknik pengambilan sampel yang digunakan adalah multistages sampling, dengan tahapan sebagai berikut:

- Tahap I, yaitu menentukan TPI sebagai tempat pengambilan sampel. Berdasarkan jumlah produksi ikan demersal terbesar dan alat tangkap, terpilih TPI Tanjungsari dan PPP Tasikagung di Kecamatan Rembang.

Tabel 1

Produksi Ikan Demersal Menurut Jenis dan Tempat Pelelangan Ikan (TPI) di Kabupaten Rembang Tahun 2005

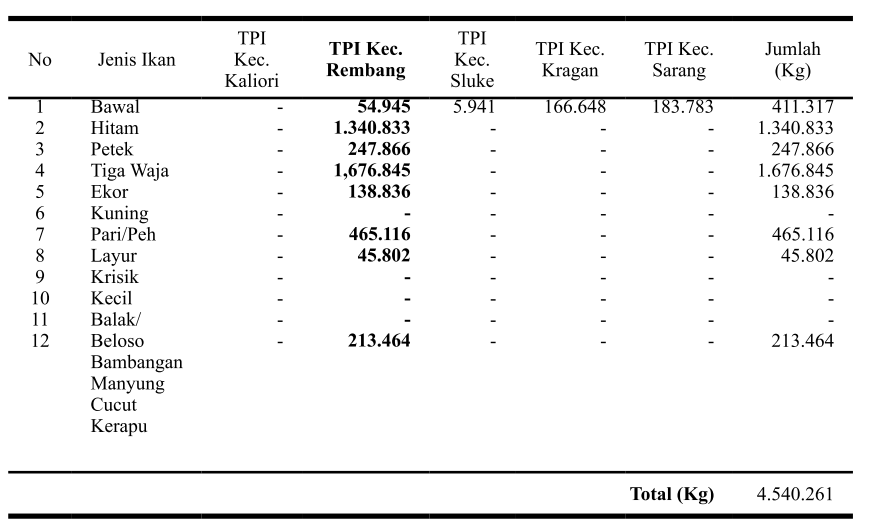

Sumber: Dinas Perikanan dan Kelautan Kabupaten Rembang (diolah), 2005

- Tahap II, yaitu menentukan jumlah sampel. Sampel penelitian (bioekonomi) ini adalah kapal motor dengan alat tangkap cantrang. Pengambilan sampel diambil secara terkuota (quoted sampling). Secara terkuota, dengan $\mathrm{n}=100$ 
- Tahap III, yaitu pengambilan sampel berdasarkan pola kerja/penangkapan, dengan satuan lama berlayar (hari), yaitu kapal harian (1 hari) dengan ukuran ratarata $<12$ GT, kapal sarangtayu (4-7 hari) dengan ukuran rata-rata $12-20$ GT, dan kapal bambangan (15-25 hari) dengan ukuran rata-rata $>21 \mathrm{GT}$.

Tabel 2

Jumlah Sampel Kapal Motor Cantrang

\begin{tabular}{|c|c|c|c|c|}
\hline Populasi & $\begin{array}{l}\text { Sub Populasi } \\
\text { (TPI/Jenis Kapal) }\end{array}$ & Jumlah & $\begin{array}{c}\text { Sampel } \\
\text { (TPI/Jenis Kapal) }\end{array}$ & Jumlah \\
\hline $225^{*}$ & - TPI Tanjungsari & & - TPI Tanjungsari & \\
\hline \multirow[t]{4}{*}{$\begin{array}{l}\text { (Kapal } \\
\text { Motor dan } \\
\text { Non-Motor) }\end{array}$} & $\begin{array}{l}\text { Harian } \\
\text { - } \quad \text { TPI Tasikagung }\end{array}$ & 45 & $\begin{array}{l}\text { Harian } \\
\text { - } \quad \text { TPI Tasikagung }\end{array}$ & 36 \\
\hline & Sarangtayu & 49 & Sarangtayu & 32 \\
\hline & Bambangan & 45 & Bambangan & 32 \\
\hline & Total Sub Populasi & $139^{* *}$ & Total Kuota Sampel & 100 \\
\hline
\end{tabular}

Sumber: *) Dinas Perikanan dan Kelautan Kab. Rembang, 2007

**) TPI Tanjungsari dan Tasikagung, Kab. Rembang 2007

\section{Metode Analisis}

Dalam melakukan analisis Bioekonomi, secara runtut tahapannya adalah:

1. Standarisasi alat tangkap, namun, karena pada daerah penelitian kapal cantrang merupakan kapal tunggal (single operator) untuk perikanan demersal, maka analisis standarisasi alat tangkap tidak dilakukan.

2. Pendugaan parameter biologi: Model Surplus Produksi

3. Pendugaan parameter ekonomi: Model Bioekonomi Gordon Schaefer

\section{HASIL PENELITIAN DAN PEMBAHASAN}

\section{Analisis Bioekonomi: Aspek Biologi}

Pendugaan potensi lestari ikan demersal merupakan angka yang menunjukkan jumlah produksi ikan demersal yang lestari dan merupakan output analisis Metode Surplus Produksi Schaefer. Besarnya hasil dinyatakan dengan Catch Per Unit Effort (CPUE) yang didapat dari jumlah produksi ikan demersal dibagi dengan jumlah alat tangkap cantrang yang dipakai. (Tabel 3)

\section{Tabel 3}

Perkembangan Produksi (Catch) Ikan Demersal, Effort (Unit Kapal), dan CPUE (Catch per Unit of Effort) di Kabupaten Rembang Tahun 2001-2006

\begin{tabular}{cccc}
\hline Tahun & Catch $(\mathrm{Kg})$ & Effort (Unit) & CPUE (Kg/Unit) \\
\hline 2001 & 4.804 .559 & 111 & $43.284,32$ \\
2002 & 5.764 .564 & 124 & $46.488,42$ \\
2003 & 2.870 .290 & 88 & $32.616,93$ \\
2004 & 3.556 .155 & 73 & $48.714,45$ \\
2005 & 4.535 .439 & 231 & $19.633,94$ \\
2006 & 3.227 .845 & 225 & $14.345,98$ \\
\hline
\end{tabular}

Sumber : Dinas Perikanan dan Kelautan Kabupaten Rembang (diolah), 2007

Analisis regresi antara upaya tangkap (effort) dengan CPUE pada sumberdaya ikan demersal di Kabupaten Rembang menghasilkan hubungan sebagai berikut:

$$
\text { CPUE }=60243.158-183.539 \text { EFFORT }
$$

Hubungan tersebut artinya setiap terjadi peningkatan effort sebanyak 1 unit maka CPUE akan turun sebesar 183,539 kg per tahun. Hal ini menunjukkan kondisi sumberdaya ikan demersal telah mengalami overfishing secara biologi. 


\section{Gambar 7}

\section{Hubungan Antara CPUE dan Upaya Tangkap (Effort) \\ Tahun 2001-2006}

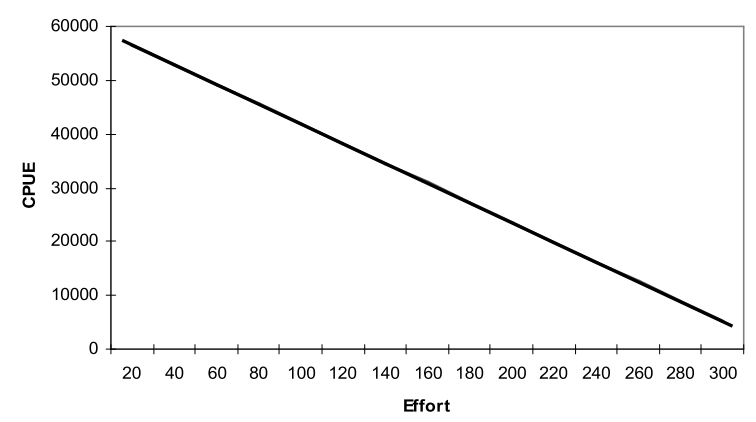

Sumber: Dinas Perikanan dan Kelautan Kab. Rembang, 2007 (diolah dengan Ms.Excel)

Pada gambar 7, terlihat bahwa semakin tinggi upaya penangkapan ikan (effort), semakin rendah hasil tangkapan per unitnya (CPUE). Selain itu, persamaan regresi menghasilkan nilai $\alpha=60243,158$ dan $\beta=-183,539$ yang kemudian dimasukkan ke dalam rumus Maximum Sustainable Yield (MSY), sehingga menghasilkan nilai effort yang $\left(\mathrm{E}_{\mathrm{MSY}}\right)$ yaitu 164 unit kapal cantrang, sedangkan nilai tangkapan (catch) lestari $\left(\mathrm{C}^{\mathrm{MSY}}\right)=4.943 .425,25 \mathrm{~kg}$.

\section{Gambar 8}

Hubungan Antara Upaya Lestari $\left(\mathrm{E}_{\mathrm{MSY}}\right)$ dan Tangkapan Lestari $\left(\mathrm{C}_{\mathrm{MSY}}\right)$ Sumberdaya Ikan Demersal di Kabupaten Rembang

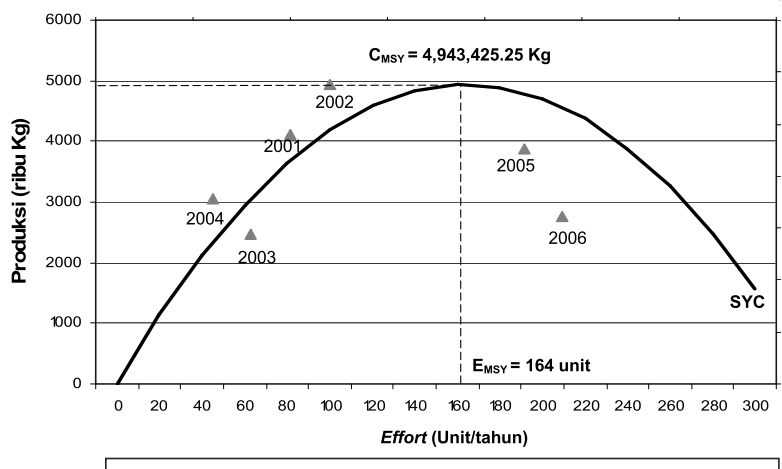

$\Delta$ Produksi Aktual - SYC- Sustainable Yield Curve (Kurva Lestari)

Sumber: Dinas Perikanan dan Kelautan Kab. Rembang, 2007 (diolah dengan Ms.Excel)
Kurva produksi lestari (lihat Gambar 8 dan Tabel 4), menunjukkan bahwa tingkat pemanfaatan sumberdaya ikan demersal di Kabupaten Rembang pada tahun 2001 (97 persen), 2002 (117 persen), dan 2005 (92 persen) dan mengalami overfishing pada tahun 2002 atau melampaui Total Allowable Catch (FAO, 1995) yaitu 80 persen dari nilai produksi lestari $\left(\mathrm{C}_{\mathrm{MSY}}\right)$.

Tabel 4

Tingkat Pemanfaatan Sumberdaya Ikan Demersal di Kabupaten Rembang Tahun 2001-2006

\begin{tabular}{ccccc}
\hline Tahun & $\begin{array}{c}\text { Catch- } \\
\text { Aktual }(\mathrm{Kg})\end{array}$ & $\begin{array}{c}\text { Catch- } \\
\text { Lestari }(\mathrm{Kg})\end{array}$ & TAC (Kg) & Pemanfaatan*) \\
\hline 2001 & 4.804 .559 & $4.943 .425,25$ & 3.954 .740 & $97 \%$ \\
2002 & 5.764 .564 & $4.943 .425,25$ & 3.954 .740 & $117 \%$ \\
2003 & 2.870 .290 & $4.943 .425,25$ & 3.954 .740 & $58 \%$ \\
2004 & 3.556 .155 & $4.943 .425,25$ & 3.954 .740 & $72 \%$ \\
2005 & 4.535 .439 & $4.943 .425,25$ & 3.954 .740 & $92 \%$ \\
2006 & 3.227 .845 & $4.943 .425,25$ & 3.954 .740 & $65 \%$ \\
\hline
\end{tabular}

Sumber: Dinas Perikanan dan Kelautan Kabupaten Rembang (diolah), 2007

\section{Analisis Bioekonomi: Aspek Ekonomi}

Pendugaan aspek potensi ekonomi ikan demersal dengan unit kapal cantrang adalah dengan faktor harga (price) dan biaya (cost). Biaya pengoperasian kapal cantrang dalam penangkapan ikan demersal dibagi dalam biaya tetap (fixed cost) dan biaya variabel (variabel cost). Biaya tetap yang dimaksudkan dalam penelitian ini yaitu: biaya penyusutan, biaya investasi, administrasi, dan biaya perawatan atau pemeliharaan. Sedangkan, biaya tidak tetap yaitu: biaya operasional, yang meliputi biaya bahan bakar, konsumsi, bongkar muat, upah ABK. (lihat Tabel 5). 
Tabel 5

Uraian Biaya Rata-rata Penangkapan Ikan Demersal (Unit/Tahun)

\begin{tabular}{|c|c|c|c|}
\hline No & Jenis & Jumlah (Rp) & $\begin{array}{c}\text { Kontribusi } \\
(\%)\end{array}$ \\
\hline 1 & Biaya Investasi & 131.155 .000 & 23,43 \\
\hline 2 & Biaya Penyusutan & $23.969 .199,36$ & 4,28 \\
\hline 3 & $\begin{array}{l}\text { Biaya } \\
\text { Pemeliharaan }\end{array}$ & $10.684 .545,5$ & 1,91 \\
\hline 4 & Biaya Administrasi & 3.464 .144 & 0,62 \\
\hline 5 & Biaya Operasional & 390.464 .853 & 69,76 \\
\hline & Total & $559.737 .741,9$ & 100 \\
\hline
\end{tabular}

Sumber: Data primer (diolah), 2007

Adapun harga (price) dalam penelitian ini merupakan harga rata-rata penjualan ikan dari dua musim penangkapan yang berbeda, yaitu musim puncak dan musim biasa. Harga rata-rata $(\bar{x})$ adalah harga rata-rata dari total hasil tangkapan kapal cantrang yang diproporsikan terlebih dahulu dengan jumlah tangkapannya $(\mathrm{kg})$.

\section{Tabel 6}

Uraian Penentuan Harga Rata-rata Ikan Demersal

\begin{tabular}{llrrcr}
\hline No & Jenis Ikan & \multicolumn{1}{c}{ Kg } & Proporsi & $\begin{array}{c}\text { Harga Rata- } \\
\text { Rata }\end{array}$ & $\begin{array}{c}\text { Harga } \\
\text { Proporsi }\end{array}$ \\
\hline 1 & Tiga Waja & 2.435 & 0,69 & 2.320 & 1.604 \\
2 & Ekor kuning & 135.098 & 38,38 & 1.775 & 6.8134 \\
3 & Bawal Hitam & 29 & 0,01 & 82.500 & 674 \\
4 & Petek & 9.806 & 2,79 & 1.973 & 5.497 \\
5 & Layur & 336 & 0,10 & 2.853 & 272 \\
6 & Balak/Beloso & 7.224 & 2,05 & 3.333 & 6.841 \\
7 & Pari/Peh & 3.800 & 1,08 & 4.327 & 4.672 \\
8 & Kerapu & 10.130 & 2,88 & 15.316 & 44.077 \\
9 & Manyung & 1.335 & 0,38 & 3.600 & 1.365 \\
10 & Kakap Merah & 1.094 & 0,31 & 22.833 & 7.100 \\
11 & Kurisi & 132.690 & 37,70 & 3.995 & 150.614 \\
12 & Abangan & 46.764 & 13,29 & 3.569 & 47.422 \\
13 & Cucut & 1.250 & 0,36 & 8.000 & 2.841 \\
\hline & & & & Harga Rata- & $\mathbf{2 6 . 2 3 9}$ \\
\hline
\end{tabular}

Sumber: Data primer (diolah), 2007

Model ekonomi (lihat Gambar 9) dari optimasi pemanfaatan sumberdaya ikan demersal di Kabupaten Rembang ditunjukkan oleh hasil perhitungan bioekonomi yang dijelaskan melalui tiga jenis pengelolaan sumberdaya ikan demersal yang dibandingkan dengan kondisi aktual ( $\bar{x}$ ) sumberdaya ikan demersal selama periode tahun 2001-2006. Ketiga jenis pengelolaan yang dimaksud adalah Maximum Sustainable Yield (MSY), Maximum Economic Yield (MEY), dan Open Accsess Equilibrium (OAE). Berikut ini adalah analisis berdasarkan ketiga jenis pengelolaan tersebut:

\section{Gambar 9}

\section{Model Ekonomi Ikan Demersal yang Lestari} di Kabupaten Rembang

\section{Analisis Bioekonomi}

\section{Cooficients}

\begin{tabular}{|c|c|c|c|}
\hline$\alpha$ & $\beta$ & $p(\mathrm{Rp} / \mathrm{kg})$ & $c$ (Rp/unit) \\
\hline 60243.16 & 183.54 & 26239.44 & 559737741.86 \\
\hline
\end{tabular}

Results

\begin{tabular}{|c|c|c|c|c|}
\hline \multirow{2}{*}{} & \multicolumn{4}{|c|}{ Solusi Bioekonomi } \\
\cline { 2 - 5 } & MSY & OAE & MEY & Aktual $(\overline{\boldsymbol{X}})$ \\
\hline $\begin{array}{c}\text { Effort } \\
\text { (unit) }\end{array}$ & 164.12 & 212.01 & 106.00 & 142.00 \\
\hline $\begin{array}{c}\text { Catch } \\
(\mathrm{kg})\end{array}$ & 4943425.25 & 4522489.23 & 4323595.25 & 4126475.33 \\
\hline $\begin{array}{c}\text { Economic } \\
\text { rent }(\mathrm{Rp})\end{array}$ & 37850932124.34 & 0.00 & 54114923817.75 & 28793638872.78 \\
\hline
\end{tabular}

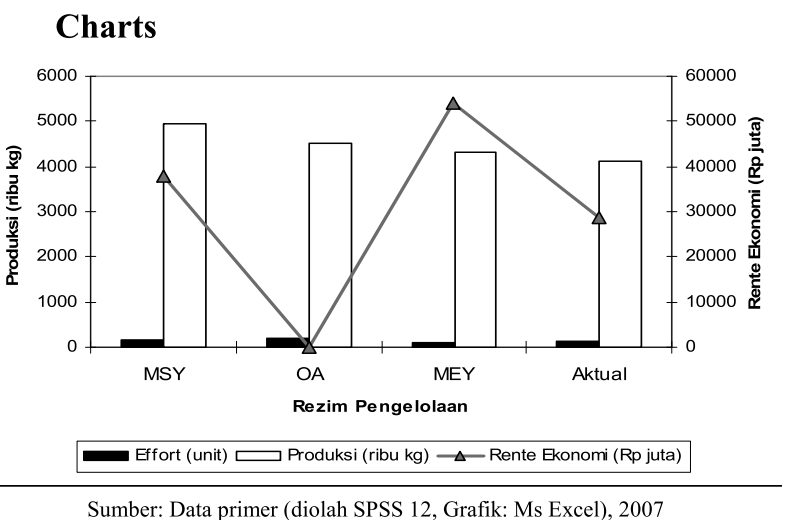

1. Aspek Tangkapan (Catch)

a. Tingkat produksi sumberdaya ikan demersal memiliki pada kondisi pengelolaan MSY adalah sebesar 4.943.425,25 kg per tahun, MEY 
dengan produksi sebesar 4.323.595,25 $\mathrm{kg}$ per tahun, sedangkan OAE tingkat produksinys sebesar $4.522 .489,23 \mathrm{~kg}$ per tahun, adapun tingkat produksi pada kondisi aktual $(\bar{x})$ selama periode tahun 2001-2006 adalah sebesar 4.126.475,33 per tahun.

b. Tingkat produksi pada kondisi aktual ( $\bar{x})$ selama periode tahun 2001-2006 adalah $4.126 .475,33 \mathrm{~kg}$ per tahun, telah mendekati tingkat produksi pada kondisi MEY dengan produksi 4.323.595,25 $\mathrm{kg}$ per tahun, namun cukup jauh untuk mencapai kondisi MSY dengan produksi $4.943 .425,25 \mathrm{~kg}$ per tahun.

c. Secara biologi tingkat produksi pada kondisi aktual $(\bar{x})$ selama periode tahun 2001-2006 masih dapat ditingkatkan sebesar 197.119,92 kg per tahun untuk mencapai kondisi MEY, dan dapat ditingkatkan sebesar 816.949,92 kg per tahun untuk mencapai kondisi MSY. Namun, tingkat produksi pada kondisi aktual terhadap MSY telah mencapai 83 persen, atau melebihi TAC sebesar 80 persen. Sehingga, kondisi pengelolaan yang optimal adalah pada tingkat produksi MEY.

\section{Aspek Unit Kapal (Effort)}

a. Tingkat upaya penangkapan (unit kapal cantrang) terbesar terjadi pada kondisi pengelolaan OAE sebesar 212 unit kapal cantrang per tahun, jauh lebih besar kondisi aktual $(\bar{x})$ selama periode tahun 2001-2006, yaitu 142 unit per tahun, sedangkan pada kondisi MSY sebanyak 164 unit per tahun dan pada kondisi MEY sebanyak 106 unit per tahun.

b. Tingkat upaya penangkapan pada kondisi aktual $(\bar{x})$ selama periode tahun 20012006 sebesar 142 unit per tahun lebih besar dari kondisi MEY yang sebesar 106 unit per tahun, namun mendekati kondisi
MSY yaitu 164 unit per tahun. Meskipun jumlah unit kapal cantrang dapat ditambah hingga 22 unit per tahun (kondisi MSY), namun tingkat produksinya bertentangan dengan TAC. Sehingga, kondisi pengelolaan yang optimal adalah pada tingkat upaya penangkapan (effort) MEY.

c. Tingkat upaya penangkapan (effort) pada kondisi OAE disebut sebagai bioeconomic equilibrium of open acces fishery. Kondisi ini menimbulkan terjadinya misalokasi sumberdaya alam karena kelebihan faktor produksi (tenaga kerja dan modal) dan juga menimbulkan economic overfishing.

\section{Aspek Profit (Economic Rent)}

a. Tingkat profit per tahun pada ketiga jenis pengelolaan dipengaruhi oleh total penerimaan (TR) dan total biaya (TC) setiap unit kapal cantrang per tahun. Tingkat profit pada kondisi MEY $\left(\mathrm{ER}_{\mathrm{MEY}}\right)$ merupakan Maximum Economic Rent (MER) adalah yang paling besar dibandingkan dengan kondisi pengelolaan lainnya.

b. Tingkat profit pada kondisi aktual $(\bar{x})$ selama periode tahun 2001-2006 adalah Rp 28.793.638.872,78 per tahun, yang lebih sedikit jika dibandingkan pada kondisi MEY sebesar Rp 54.114.923.817,75 per tahun dan kondisi MSY sebesar Rp 37.850.932.124,34 per tahun., tetapi lebih besar dari kondisi OAE dengan tingkat profit $\mathrm{Rp} 0$ per tahun.

c. Tingkat profit pada kondisi aktual $(\bar{x})$ selama periode tahun 2001-2006 masih dapat dikembangkan untuk mencapai tingkat proft (ER) optimum pada kondisi MEY, namun dengan syarat mengurangi jumlah unit kapal cantrang (effort) sebesar 36 unit per tahun, sehingga akan mendapat tambahan profit sebesar Rp 25.321.284.944,97 per tahun. 
Sehingga kondisi pengelolaan yang terbaik dengan mempertimbangkan TAC sebesar 80 persen dari potensi lestari (MSY), maka kondisi pengelolaan MEY merupakan kondisi yang paling baik dalam mengelola sumberdaya ikan demersal di Kabupaten Rembang, yaitu pada tingkat produksi $\left(\mathrm{C}_{\mathrm{MEY}}\right)$ sebesar 4.323.595,25 $\mathrm{kg}$ per tahun, dengan jumlah kapal cantrang $\left(\mathrm{E}_{\mathrm{MEY}}\right)$ sebesar 106 unit per tahun, yang menghasilkan tingkat profit $\left(\mathrm{ER}_{\mathrm{MEY}}\right)$ sebesar $\mathrm{Rp}$ 54.114.923.817,75 per tahun. Tidak dapatnya memaksimalkan tingkat produksi ke kondisi $\mathrm{C}_{\mathrm{MSY}}$, karena tingkat produksi aktual $(\bar{x})$ selama periode tahun 2001-2006 terhadap $\mathrm{C}_{\mathrm{MSY}}$ telah mencapai 83 persen, atau melebihi TAC sebesar 80 persen.

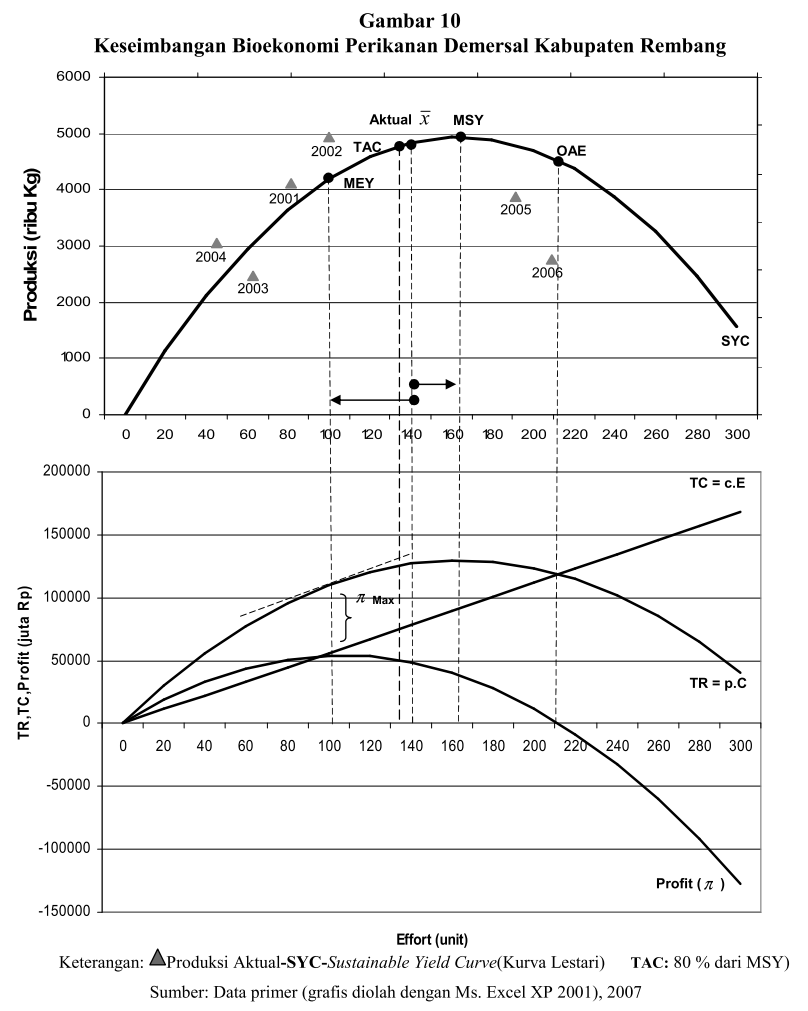

Sumber: Data primer (grafis diolah dengan Ms. Excel XP 2001), 2007

\section{Economic Overfishing Usaha Perikanan Tangkap Ikan Demersal}

Pada kondisi lapangan, tingkat profit (ER) pada usaha perikanan tangkap ikan demersal yang dilakukan oleh pemilik kapal cantrang memiliki nilai minus sebesar $\mathrm{Rp}-306.537 .320,72$ per tahun. Kondisi hasil survei diperkuat dengan data Dinas Perikanan dan Kelautan bahwa jumlah unit kapal cantrang telah meningkat mencapai 231 (2005) dan 225 (2006). Peningkatan jumlah unit kapal cantrang telah melewati jumlah unit pada kondisi open accsess $\left(\mathrm{E}_{\mathrm{OAE}}\right)$, sebanyak 212 unit kapal. Tingkat profit yang minus atau Rp 0 per tahun sesuai dengan profit pada kondisi OAE $\left(\mathrm{ER}_{\mathrm{OAE}}\right)$ yaitu sebesar Rp 0 per tahun. Kondisi tersebut disebut sebagai economic overfishing

Tabel 7

Nilai TR, TC, dan ER/Profit per Tahun pada Usaha Perikanan Tangkap Ikan Demersal di Kabupaten Rembang

\begin{tabular}{lc}
\hline Komponen Usaha & Nilai (Rp) \\
\hline TR (Non Ikan Demersal) & Rp 348.243.326,93 \\
TR (Ikan Demersal) & Rp 253.200.421,14 \\
TC & Rp 559.737.741,86 \\
ER (Ikan Demersal) & -Rp 306.537.320,72 \\
\hline ER (Total) & Rp 41.706.006,21 \\
\hline
\end{tabular}

Sumber: Data primer (diolah dengan SPSS 12), 2007

Kondisi profit tersebut akan berbeda jika profit ikan demersal (ER Ikan Demersal) ditambahkan dengan total penerimaan dari jenis non ikan demersal atau TR Non Ikan Demersal (lihat Tabel 7), seperti: ikan demang, kembung, kapasan (kelompok ikan pelagis), cumi-cumi, nos, dan lainya. Maka secara keseluruhan, ER Ikan Demersal $\mathrm{Rp}-306.537 .320,72$ per tahun ditambah dengan TR Ikan Non-Demersal sebesar Rp 348.243.326,93 per tahun, maka ER 
Total dari rata-rata per unit kapal cantrang di Kabupaten Rembang adalah Rp 41.706.006,21 per tahun. Hal tersebut yang menyebabkan tetap berlangsungnya kegiatan usaha penangkapan, walaupun kondisi perikanan demersal sudah tidak menguntungkan secara ekonomi.

\section{KESIMPULAN DAN SARAN}

1. Hubungan antara upaya tangkap (effort) dengan CPUE pada sumberdaya ikan demersal adalah CPUE $=60243.158-183.539$ EFFORT, artinya setiap terjadi peningkatan effort sebanyak 1 unit maka CPUE akan turun sebesar 183,539 $\mathrm{kg}$ per tahun. Hal ini menunjukkan kondisi sumberdaya ikan demersal telah mengalami overfishing secara biologi.

2. Kondisi pengelolaan MEY terlihat lebih ramah lingkungan dan menguntungkan secara ekonomi dibandingkan dengan kondisi pengelolaan OAE dan MSY. Kondisi pengelolaan MEY menghasilkan upaya optimum $\left(\mathrm{E}_{\mathrm{MEY}}\right)$ sebanyak 106 unit kapal per tahun, yang menghasilkan tingkat produksi optimum $\left(\mathrm{C}_{\mathrm{MEY}}\right)$ sebesar $4.323 .595,25 \mathrm{~kg}$ per tahun, sehingga menghasilkan profit optimum $\left(\mathrm{ER}_{\mathrm{MEY}}\right)$ yaitu $\mathrm{Rp}$ 54.114.923.817,75 per tahun.

\section{DAFTAR PUSTAKA}

Anderson, LG, 1986, The Economic of Fisheries Management, The John Hopkins University: USA.

Clark F.W, 1985. Bioeconomic Modelling and Fisheries Management. John Willey and Sons Inc, New York.

Dinas Kelautan dan Perikanan Kabupaten Rembang, 2007, Profil Perikanan Kabupaten Rembang, Rembang (unpublished)
Dwiponggo, Aloysius, 1992, Pengkajian Perkiraan Potensi Sumberdaya Perikanan dan Tingkat Pengusahaanya di Perairan Utara Jawa, Balai Penelitian Perikanan Laut. Departemen Perikanan, Jakarta

Dirjen Pengawsan Sumberadaya Kelautan dan Perikanan, 2004, Standar Operasional dan Prosedur Pengawasan Penangkapan Ikan, Jakarta.

Fauzi dan Anna, 2004, Permodelan Sumberdaya Perikanan dan Kelautan, PT. Gramedia Pustaka: Jakarta

Hardi, 1994, Efisiensi Ekonomi Usaha Penangkapan Dengan Alat Tangkap Cantrang dan Mini Purseine di Kabupaten Pemalang, Skripsi, Fakultas Peternakan, Universitas Diponegoro, Semarang (unpublished)

Himawan, Arif, 2005, Analisis Efisiensi Alat Tangkap Perikanan Gill Net dan Cantrang (Studi di Kabupaten Pemalang, Jawa Tengah), Tesis, Pascasarjana MIESP, Universitas Diponegoro, Semarang (unpublished)

Misuari, 2006, Pemanfaatan Sumberdaya Perikanan Cantrang Sesuai Dengan Code of Conduct For Responsible Fisheries (CCRF) di Perairan Rembang Jawa Tengah, Skripsi, Fakultas Perikanan dan Ilmu Kelautan, Universitas Diponegoro, Semarang (unpublished)

MukhlisaA. Ghaffar, 2006, Optimasi Pengembang Usaha Perikanan Mini Purse Seine di Kabupaten Jeneponto Provinsi Sulawesi Selatan,Tesis, Pascasarjana, Institut Pertanian Bogor (IPB), Bogor

Mulyadi, Eris, 2007, Analisis Sumberdaya Ikan Demersal di Perairan Perbatasan Kalimantan Timur, Tesis, Magister Manajemen Sumberdaya Panatai, Pascasarjana, Universitas Diponegoro, Semarang (unpublished) 
Purwanto, 2006, Bioekonomi Perikanan, Departemen Kelautan dan Perikanan: Jakarta

Riyadi, Dedi M. Masykur, 2004, Kebijakan Pembangunan Sumberdaya Pesisir Sebagai Alternatif Pembangunan Indonesia Masa Depan, dalam Sosialisasi Nasional Program MFCDP, 22 September 2004, www.bappenas. go.id

Sparre, Per dan Venema, S, 1999, Introduksi Pengkajian Stok Ikan Tropis, Pusat
Penelitian dan Pengembangan

Perikanan, Badan Penelitian dan Pengembangan Pertanian: Jakarta

Sutardji, 2006, Potensi dan Tingkat Pemanfaatan Sumberdaya Ikan di Perairan Rembang Jawa Tengah, Skripsi, Fakultas Perikanan dan Ilmu Kelautan, Universitas Diponegoro, Semarang (unpublished)

Triarso, Iman, 2006, Model Matematis Bioekonomi Gordon Schaefer, Bahan Ajar Kuliah, Fakultas Perikanan dan Ilmu Kelautan, Universitas Diponegoro, Semarang 